ance at the College of Medicine, Newcastle-uponTyne. During the year so spent the student must attend the medical and surgical practice and clinical lectures at the Infirmary, which contains over 400 beds. No residence at Durham is necessary. The remaining four years of the curriculum may be spent at Newcastle-upon Tyne or at one or more of the recognised medical schools.

\section{UNIVERSity oF EDINBURGH.}

To obtain the Edinburgh medical degree it is necessary to pass the Preliminary Examination or its recognised equivalent, and to pass four professional examinations. The first is in botany, zoology, physics, and chemistry; the second in anatomy, and physiology, the third in pathology, materia medica, and therapeutics, and the final in surgery, clinical surgery, medicine, clinical medicine, midwifery, clinical gynæcology, forensic medicine, and public health.

The degree of M.B. is not conferred separately from that of Ch.B. In order to obtain the degree it is necessary to spend at least two of the five years of medical study in the University of Edinburgh.

University of Aberdeen.

The regulations are practically the same as those given for Edinburgh. Clinical instruction is obtained in the Royal Infirmary, which contains 250 beds, in the Sick Children's Hospital, and several other institutions, including the Royal Lunatic Asylum and the City Fever Hospital.

The University of Sheffield.

Degrees of Bachelor of Medicine and Bachelor of Surgery. - A candidate for the degrees of M.B., Ch.B., shall produce certificates that he will nave attained the age of 21 years on the day of graduation; that he has pursued the courses of study required by the University Regulations during a period of not less than five years subsequently to the date of his registra- tion as a medical student by the General Medical Council, three of such years at least having been passed in the University, and one year at least having been passed in the University subsequently to the date of passing the First Examination. Three examinations must be passed.

The subjects of the First Examination are Chemistry, Physics, and Biology.

The subjects of the Second Examination are Anatomy, Physiology, Materia Medica, and Pharmacy.

The subjects of the Third and Final Examination are divided into two parts, namely, A (Forensic Medicine and Toxicology, Public Health, and Pathology and Morbid Anatomy), and B (Medicine, including Pharmacology and Therapeutics, Mental Diseases, and Diseases of Children, Surgery, Obstetrics, and Gynæcology). Candidates may present themselves for examination in both parts on the same occasion or separately, but Part A may not be passed before the completion of the fourth year of study. Candidates for the whole examination, or for Part B, must have completed the fifth year of study. Candidates for the degree of Doctor of Medicine must have passed the examination for the degrees of M.B., Ch.B., at least one year previously, must present a thesis embodying observations in some subject approved by the Professor of Medicine, and must pass an examination in the Principles and Practice of Medicine. Candidates for the degree of Ch.M. must have passed the examination for the degrees of M.B., Ch.B., at least one year previously, and must, since taking the degrees of M.B., Ch.B., have held for not less than six months a surgical appointment in a public hospital or other public institution affording full opportunity for the study of Practical Surgery. The subjects of examination are Systematic, Clinical, and Operative Surgery, Surgical Anatomy, Surgical Pathology, and Bacteriology.

\title{
THE FELLOWSHIP.
}

The Fellowship of the Royal College of Surgeons, justly esteemed as the premier qualification that the student can obtain in surgery, holds out certain attractions which the student would do well carefully to weigh. To obtain it it is necessary to pass two examinations, a preliminary and a final.

The Preliminary examination takes place twice every year, in May and in November, and is held in London. The subjects are Anatomy and Physiology, and candidates must have passed the second Conjoint examination or some other equivalent examination which exempts them from it. They must also (except in the case of qualified men) have spent two winter sessions in dissections and attendance at physiology classes at a recognised school. The examination is partly oral and partly written. Two papers are set, one in physiology and one in anatomy, four questions being given with an allowance of three hours for each paper. The scope of the questions can be easily seen by studying the papers set during the past few years, copies of which may be obtained on application to the Secretary, Examination Hall, Embankment. The oral examinations are two, lasting fifteen minutes each, in the two subjects. To a very large extent the questions asked at the vivas are objective, "spotting," and straightforward questions on regional anatomy, embryology, special anatomy, physiology and histology being usually in the programme. The examination has the reputation of being unusually stiff, with more than the average element of luck appertaining to it, but its difficulty need not frighten the average student or practitioner who is willing to pay special attention to the two subjects. A good, sound knowledge of anatomy and physiology is required, and if the candidate has been diligent at his practical work in the dissecting room and laboratory, and has supplemented the knowledge there gained by reading, he stands a good chance of success.

The examination for the final fellowship takes place in May and November of each year, and consists of written papers, viva voces, clinicals, and operative surgery. The fee for the examination is $£ 1515 \mathrm{~s}$., and candidates are required to be members of the college who have been six years in practice or the study of medicine. 